None the less, some interesting items of social history escape the editor's scissors. For example, it is evident that selfexperiments with a whole variety of drugs, including caffein, ether, hashish, laudanum and morphine, were regarded as perfectly in order even in the family of a Presbyterian College President. Such "experiments", appear to have been regarded as healthy explorations of the range of consciousness and as carrying no social or medical stigma whatsoever. It would be interesting to trace the reasons why such widely disseminated personal idiosyncracies apparently failed to produce anything remotely approaching the student drug culture of today.

O. L. Zangwill is Professor of Experimental Psychology at the University of Cambridge.

\title{
Transformations in magma physics
}

\section{M.J. O'Hara}

Physics of Magmatic Processes. Edited by R.B. Hargraves. Pp.585. ISBN hbk 0-69108259-6; ISBN pbk 0-691-08261-8. (Princeton University Press: 1980 .) Hbk $\$ 40, £ 24$; pbk $\$ 15, £ 9.30$.

THIS companion volume to Evolution of the Igneous Rocks; Fiftieth Anniversary Perspectives (Princeton, 1979) emerges from a conference commemorating the fiftieth anniversary of Bowen's great publication. Written by an impressive list of experts, it contains 11 chapters on a range of aspects of the physics, thermochemistry and trace element chemistry of magmas.

In the opening contribution, P.C. Hess discusses the structure of silicate liquids and indicates the importance of its influence on liquid immiscibility and distribution coefficients for trace elements. His account, though useful, would have been more valuable with the inclusion of the instructive saga of the variations of nickel distribution between olivine and liquid, and if the implications of changes in liquid structure with pressure (and with time in an experiment) for measured distribution coefficients had been surveyed in more detail.

D.F. Weill, R. Hon and A. Navrotsky next illustrate the progress made, despite considerable difficulties, in the prediction of crystal-liquid phase equilibria from thermodynamic data. In this context, it is worthy of note that experimental determination has a more important future than some would have predicted five years ago. Progress in determination of the important physical parameters of magmas is covered by I. Kushiro. He emphasizes the importance of the transition from four-fold to six-fold coordination of aluminium in controlling increase of density, decrease of viscosity and change of liquid structure in the $10-20 \mathrm{~kb}$ range. (The mind leaps to the possible effects of the same transition in the coordination of silicon, which should produce yet more dramatic changes of such properties at pressures encountered within the lower part of the upper mantle - it is a pity that Kushiro does not speculate on this.) He does, however, discuss the overall implications of the changes of viscosity and density for rates of magma movement, changes in volatile solubility and the efficiency of magma extraction, crystal- liquid fractionation and diffusive processes.

S.R. Hart and C.J. Allegre review the field of trace element and isotope geochemistry, before going on to provide an excellent summary of the "traditional" (or pre-1980) theory of the petrogenesis of mafic and granitic rocks. The more complicated but entirely plausible trace element models (touched on briefly in this chapter), combined with new understanding of the physics of magma mixing, have transformed thinking on the subject; fractionating magma chambers fed by uniform parent liquids can erupt lava suites which must (traditionally) be interpreted as partial melting products of heterogeneous mantle sources. The rehabilitation of assimilation and contamination is at hand, and increasing evidence for diffusive differentiation of trace elements (and isotopes?) in magma chambers may shortly overwhelm all other considerations. These are stirring times!

In his critical review of problems in heat flow determination and interpretation, E.R. Oxburgh concentrates on a survey of partial melting in upward convecting systems. Somewhere in this book it would have been appropriate to refer to the vexed question of density constraints on mantle plumes and to the inverse possibility that partial melting at the base of the mantle precedes and drives the convective motions. An unconsidered possibility is that partial melts may become denser than olivine (but not denser than a bulk residue containing silica-rich garnet rather than pyroxene) near the base of the upper mantle, hence allowing upward motion of low percentage partial melts, downward movement of high percentage melts and complex redistribution of heat-producing elements.

Whereas the first five chapters are models of clarity, H.R. Shaw's contribution is distinctly tough going. In almost mystic prose he explores possible relationships between stress fields, rates and volumes of magma flow, and seismicity. Nevertheless, I shall be reading and re-reading this section in order to understand its implications for the (rather neglected) situations where major magma chambers intervene between source and vent, and changes in magma composition and density may become key factors in controlling magma transport. In the following contribution, F.J. Spera covers some of the same ground as Shaw but extends the discussion to many other aspects of the segregation, ascent and eruption of magmas. Major evolution of liquid composition probably occurs between source and point of eruption in most volcanic systems, and will complicate further the relationships discussed here.

In a thoughtful and stimulating contribution, T.N. Irvine documents the recent revolution in ideas concerning chemical and physical processes in slowly cooled magma chambers. This will be essential reading for anyone interested in consolidation of magmas. Irvine covers diagenesis of crystal accumulations but unfortunately only touches on fluid dynamics; it is in this latter field that some of the most spectacular progress has been made since the book went to press.

A.W. Hoffman deals with one- and two-way diffusion in magmas, making particular reference to determinative methods rather than specific applications. One of the most important questions which is discussed in detail by Hof fman concerns the possible influence of diffusion through the boundaries between individually wellmixed convecting layers in a cooling magma chamber. While crystal-liquid equilibria apply a constraint on the lowest layer - at least if the chamber is solidifying by bottom-crystallization - it does not follow that the higher layers of the magma from which lava flows are likely to be derived will be in major- or trace-element equilibrium with the "cumulate", assemblage, or even in isotopic equilibrium with it.

E. Dowty deals with the basic theory of crystal nucleation and growth. He reviews a range of factors which may affect the morphology and chemistry of growing (or dissolving) crystals, and thus the development of grain size distributions and textures of igneous rocks, stressing once again the value of experimental work. G. Lofgren continues the story of the experimental study of crystal growth and texture development, especially with regard to lunar and terrestrial basic magmas. This final contribution provides a timely review of recent activities in the field.

Like its companion volume, this book appears at the moment when igneous petrology is making its most rapid advances since Bowen's day. Consequently it, too, suffers from omissions which will prevent it from standing as a milestone on the long road towards our understanding of magmatic processes; rather, it should be appreciated as a speedometer. Nevertheless, I found the book stimulating reading and recommend it to all serious students of igneous petrology.

M.J. O'Hara is Professor and Head of the Geology Department, University College of Wales, Aberystwyth. 